\title{
Stress state inferred from b-value and focal mechanism distributions in the aftershock area of the 2005 West Off Fukuoka Prefecture earthquake
}

Keita Chiba ( $\square$ kchiba@sevo.kyushu-u.ac.jp)

Kyushu Daigaku https://orcid.org/0000-0002-2841-3371

\section{Research Article}

Keywords: b-value, Stress state, 2005 West Off Fukuoka Prefecture Earthquake, Focal mechanism, Stress tensor inversion

Posted Date: February 16th, 2021

DOI: https://doi.org/10.21203/rs.3.rs-201023/v1

License: () (1) This work is licensed under a Creative Commons Attribution 4.0 International License.

Read Full License

Version of Record: A version of this preprint was published at Pure and Applied Geophysics on March 17th, 2021. See the published version at https://doi.org/10.1007/s00024-021-02691-5. 
3 Stress state inferred from $b$-value and focal

4 mechanism distributions in the aftershock area of the

52005 West Off Fukuoka Prefecture earthquake

6

7 Keita Chiba $^{1 *}$

8

9 Author\#1: Keita Chiba, Institute of Seismology and Volcanology, Faculty of Science, Kyushu University, 744 Motooka, Nishi-Ku, Fukuoka, 819-0395 Japan, kchiba@sevo.kyushu-u.ac.jp, Tel: +81 92-802-4346, ORCID: https://orcid.org/0000-0002-2841-3371 
Abstract - The spatiotemporal stress states in the aftershock region of the 2005 west off Fukuoka

19 prefecture earthquake are examined via an analysis of the $b$-values and focal mechanism solutions. The

20 aftershocks are aligned roughly NW-SE, with the southeastern part of the aftershock region believed to

21 correspond to Kego Fault, which extends beneath the Fukuoka metropolitan area. This study reveals

22 depth-dependent $b$-values in the focal region, where the $b$-values $(b=0.7-1.4)$ are generally higher above

23 the mainshock depth $(9.5 \mathrm{~km})$ and lower $(b=0.5-1.0)$ at greater depths. The shallower region possesses a

24 significant temporal increase in $b$-values, whereas a lateral $b$-value heterogeneity is observed in the

25 deeper region. The $b$-values $(b \sim 1.0)$ near the mainshock are relatively high, whereas the northwestern

26 and southeastern edges of the deep region have lower $b$-values $(b=0.5-0.7)$. On the other hand, many of

27 the focal mechanisms for the $M \geq 3.5$ events are located in the low $b$-value area of the deep region. The

28 stress-tensor inversion results reveal a change in stress state from strike-slip to strike-slip/normal faulting.

29 These findings imply that the stress state remains high and/or slightly decreased in the northwestern and

30 southeastern parts of the deep region. These results and the findings of previous research on this

31 earthquake sequence suggest that the likelihood of future large earthquakes along the southeastern part of the aftershock region should be considered relatively high.

34 Keywords: $b$-value, Stress state, 2005 West Off Fukuoka Prefecture Earthquake, Focal mechanism,

35 Stress tensor inversion

\section{Introduction}


2006). The hypocenter was located at $130.1616^{\circ} \mathrm{E}, 33.7434^{\circ} \mathrm{N}$, and $9.5 \mathrm{~km}$ depth, with a best-fit focal

41 mechanism solution showing left-lateral strike slip with a tension axis aligned $\mathrm{N} 23^{\circ} \mathrm{W}-\mathrm{S} 23^{\circ} \mathrm{E}$ (Uehira et al. 2006). Many aftershocks occurred at $1-16 \mathrm{~km}$ depth, and were distributed along a $25-\mathrm{km}-\mathrm{long} \mathrm{NW}-$

43 SE-trending linear feature (Shimizu et al. 2006; Uehira et al. 2006). The largest aftershock $\left(\mathrm{M}_{\mathrm{J}} 5.8\right)$

44 occurred near the southeastern end of the aftershock region on 20 April 2005, followed by additional aftershock activity to the southeast (e.g., Uehira et al. 2006). Numerous research studies have also investigated the coseismic slip distribution of the mainshock, spatial distribution of static stress drops, postseismic deformation, and attenuation structure in the focal region of the 2005 West Off Fukuoka Prefecture Earthquake (e.g., Asano and Iwata 2006; Horikawa 2006; Iio et al. 2006; Matsumoto, S. et al. 2009; Nakao et al. 2006; Nishimura et al. 2006). Iio et al. (2006) have provided important details for hazard assessments in the focal region via an investigation of the static stress drop distribution of the aftershocks using the waveforms from temporary seismic stations; they highlighted the possibility of a large stress concentration around the southeastern end of the aftershock area, which includes the largest aftershock.

55 Japan 1991). The southeastern extension of the aftershock region is believed to correspond to the northwestern edge of Kego Fault, which is known to be active fault (e.g., Okamura et al. 2009; Uehira et

57 al. 2006). Kego Fault runs beneath the Fukuoka metropolitan area, with a population of about 1.5 million.

58 Okamura et al. (2009) used acoustic exploration and sediment cores to investigate the paleoseismicity of

59 the Kego Fault and estimated that the latest two major earthquakes occurred 4,500-4,000 yBP and 8,500-

$606,500 \mathrm{yBP}$, respectively. These short recurrence intervals are a stark contrast to the 15,500 -year recurrence interval estimated by Shimoyama et al. (2005). These geophysical and geological results 
suggest that the next major earthquake might impact segments of Kego Fault that have not previously

63 ruptured, which run through the central part of Fukuoka City. The National Institute of Advanced

64 Industrial Science and Technology (AIST) (2005) calculated the Coulomb stress change induced by the

652005 mainshock, and found a positive stress change of up to $0.1-0.5 \mathrm{MPa}$ around the southeastern and

66 northwestern ends of the aftershock area. The probability of a $\mathrm{M}=7.0$ earthquake in the next 30 years on

67 the Kego Fault (counted from 2005) increased about 7\% due to the 2005 mainshock (AIST 2005). The

68 metropolitan area would be devastated if such a major earthquake were to occur. However, details of the

69 stress state have not been evaluated in and around the focal region, although the area remains seismically

70 active.

$71 \quad$ Here the $b$-values of the Gutenberg-Richter Law (Gutenberg and Richter 1944), which are

72 indicators of the stress state (e.g., Scholz 1968, 2015), are investigated in the aftershock region of the

732005 West Off Fukuoka Prefecture Earthquake using a seismic catalog that was compiled from data

74 recorded after the 2005 mainshock. Recently, the stress-dependent characteristics of the $b$-values were

75 used for real-time seismic hazard assessment. One of the main concerns after a large earthquake is

76 whether or not a stronger subsequent event will occur. Gulia and Wiemer (2019) examined time series of

$77 b$-values in many aftershock sequences, and found that a larger subsequent event is more likely to occur if

78 the $b$-value decreases substantially. Real-time monitoring of the $b$-value is thus considered useful to

79 estimate whether a larger subsequent event is likely. Furthermore, the focal mechanisms are inverted to

80 obtain the stress tensors and assess the present stress states in the study area. This inversion does not

81 determine the magnitude of the deviatoric stress at seismogenic depths (e.g. Gephart and Forsyth 1984;

82 Michael 1984, 1987). However, the orientation of the maximum horizontal stress axis relative to the fault

83 strike direction is useful to infer how the stress field evolves with time (e.g., Hardebeck and Hauksson 
84 2001). The style of faulting, which depends on the directions of the principal stress axes, also indicates

85 the absolute stress level from the Coulomb failure criterion (e.g., Jaeger and Cook 1979). This study aims

86 to clarify the spatiotemporal stress states as well as resolve highly-stressed areas with high likelihoods of

87 nucleating large earthquakes in the focal region, through unified analysis of $b$-values and stress tensor

88 inversions.

89

90

\section{Methods and data}

\section{1. $b$-values}

The empirical relationship between the earthquake frequency and magnitude distribution,

94 which is known as the Gutenberg-Richter Law, is a power law of the form:

$$
\log N=a-b M,
$$

where $N(M)$ is the cumulative number of earthquakes with magnitude equal to or greater than $M$, and

$a$ and $b$ are constants (Ishimoto and Iida 1939, Gutenberg and Richter 1944). The constant $b$ is termed the $b$-value, and represents the ratio of small to large earthquakes. The $b$-value depends on various

99 factors, including the stress state, strength, material heterogeneity, and thermal gradient (e.g., Mogi 1962;

100 Scholz 1968, 2015; Warren and Latham 1970; Wyss 1973; Urbancic et al. 1992), and varies between 0.5 and 1.5 for different tectonic settings, with an average value of 1.0 (Frohlich and Davis 1993). The stress-

102 dependent characteristics of the $b$-values are among the most widely studied earthquake parameters in the literature (e.g., Scholz 1968, 2015; Schorlemmer et al. 2004; Schorlemmer and Wiemer 2005). The 
104 differential stress generally increases as the $b$-value decreases, and vice versa. Many studies have

105 examined the stress states in various tectonic settings using spatiotemporal $b$-value distributions (e.g.,

106 Chiba 2019, 2020; Ghosh et al. 2008; Nanjo and Yoshida 2018; Nanjo et al. 2016, 2019; Schorlemmer et

107 al. 2004; Schorlemmer and Wiemer 2005; Tormann et al. 2015). The highly stressed areas in any tectonic

108 setting, such as regions with a large coseismic slip and large slip deficit rate, are usually characterized by

109 low $b$-values. For example, Schorlemmer and Wiemer (2005) examined the $b$-value distributions in the

110 focal area prior to the $2004 \mathrm{M}_{\mathrm{w}}$ 6.0 Parkfield Earthquake on the San Andreas Fault (California, USA), and

111 found a close spatial correspondence between low $b$-values and large coseismic slip during the

112 mainshock. Ghosh et al. (2008) found a negative correlation between the $b$-value distribution and plate

113 locking inferred from geodetic estimates of interface locking along the Cocos Plate near Nicoya

114 Peninsula, Costa Rica. Nanjo et al. (2016) analyzed the $b$-value distribution in the focal region of the

1152016 Kumamoto Earthquake, Japan, prior to the mainshock, and discovered that a zone near the

116 mainshock corresponds to a low $b$-value region. These examples verify that spatiotemporal $b$-value

117 analysis is an important and useful tool for seismic hazard assessment in regions with a high likelihood of

118 large earthquakes.

119

\section{2. b-value data and computational procedure}

122 catalog) was used for the $b$-value calculations in this study, which included 15,381 events that were

123 recorded between 12:20 on 20 April 2005 (2005.3 in decimal year) to 23:59 on 31 January 2020 (JST) in

124 the region bounded by $130.0-130.5^{\circ} \mathrm{E}, 33.55-33.85^{\circ} \mathrm{N}$, and $0.0-20.0 \mathrm{~km}$ depth. Data within one month of 
the mainshock were excluded since the events recorded during this period were highly heterogeneous and

126 the JMA catalog was incomplete. Fig. 1 shows hypocenters of the $M \geq 0.5$ events; this choice of

127 magnitude threshold is explained below.

$b$-value computations. An estimation of the magnitude of completeness $M_{c}$, which is the minimum

130 magnitude in the earthquake catalog that satisfies the power law in Eq. (1), is crucial for the $b$-value

131 analysis. The detection limits of the JMA catalog have improved significantly since 2000; $M_{c}$ is

133 Wyss 2000) was employed to investigate temporal changes in $M_{c}$ in the study area using overlapping

134500 -event windows and a 20-event step. Generally, $M_{c}<0.5$ throughout the analysis period (Fig. 2a).

135 Gridding methods were further applied by calculating the spatial distribution of $M_{c}$ using the maximum

136 curvature method (Wiemer and Wyss 2000). The $M_{c}$ cross-section for events within $5 \mathrm{~km}$ of line A-B in

137 Fig. 1 was calculated using $0.5 \mathrm{~km}$ grid spacing and a constant sampling radius of $2.5 \mathrm{~km}$, which

138 represents the optimal radius value for $b$-value computation of cross-sections, as explained below. $M_{c}$

139 varies across the study area, with $M_{c} \geq 0.5$ in the northwestern subregion (Fig. 2b). Two-step

140 screenings were therefore employed to choose $M_{c}$ for the $b$-value calculations. First, a total of 9,324

$141 M \geq 0.5$ events were used for further analysis, selected based on spatiotemporal $M_{c}$ distributions. Next,

142 local $M_{c}$ values were recalculated at each grid point for $M \geq 0.5$ events, using this catalog and the

143 maximum curvature method (Wiemer and Wyss 2000); this was a precursory step to $b$-value calculations

144 due to observed spatial variations in $M_{c}$. Events with magnitudes below each new $M_{c}$ value were

145 discarded. In addition, the maximum curvature method is known to often underestimate $M_{c}$ by 0.2 on

146 average (Woessner and Wiemer 2005); therefore, an $M_{c}$ correction of +0.2 was applied. The analysis 
147 window was divided into two periods to investigate the temporal changes in $b$-values: the approximately

148 8-month period after the mainshock (period 1: 4335 events, 12:20 JST on 20 April 2005-31 December

1492005 ) and the 2006-2020 period (period 2: 4989 events, 1 January 2006-31 January 2020). However, it is

150 insufficient to evaluate temporal changes in $b$-values using only arbitrarily-selected time windows. An

151 additional analysis, which divided the analysis window into three periods, was performed to investigate

152 the temporal changes in $b$-values in detail: period a1 was 12:20 JST on 20 April 2005-23:59 on 31

153 August 2005, and had 3298 events; period a2 was 1 September 2005-31 December 2007, with 3017

154 events; period a3 was 1 January 2008-31 January 2020, with 3009 events. This analysis was only used

155 for $b$-value calculations because there are too few available focal mechanisms to constrain stress tensor

156 inversions in three temporal subwindows.

157 Gridding methods were applied by calculating the maximum-likelihood $b$-values. Spatial $b$ -

158 value distributions were constructed to produce plan-view maps and cross-sections using gridding

159 intervals of $0.005^{\circ}$ and $0.5 \mathrm{~km}$ for the plan-view maps and cross-sections, respectively. Determining the

160 optimal sampling radii for the $b$-value calculations at each grid point is both necessary and non-trivial.

161 Fewer grid points match the required minimum number of events to constrain the $b$-values when the

162 sampling radii are small. Conversely, the resolution of the regional $b$-value heterogeneities is reduced

163 when the sampling radii are too large. The optimal sampling radius is the largest radius that still resolves

$164 b$-value heterogeneities in detail (Schorlemmer et al. 2004). The optimal sampling radius was determined

165 to be $2.5 \mathrm{~km}$ for the plan-view maps and cross-sections in this study after exploring a broad range of

166 sampling radii. The $b$-value was then calculated at each grid point via the maximum likelihood method

167 (Aki 1965):

168

$$
b=\log e /\left(M_{\text {mean }}-M_{0}\right),
$$



corresponding $b$-values were not calculated if a grid node had $<50$ events within a 2.5 -km radius.

172 (Utsu 1992), which is defined as:

$$
p=e^{(-d A / 2-2)},
$$

where $\mathrm{dA}=-2 N \ln (N)+2 N_{1} \ln \left(N_{1}+N_{2} b_{1} / b_{2}\right)+2 N_{2} \ln \left(N_{1} b_{2} / b_{1}+N_{2}\right)-2, N_{1}$ and $N_{2}$ are the 1999).

\subsection{Stress tensor inversion data and computational procedure}

185 from $>3$ stations, were inverted to determine the best-fitting normalized stress tensor for each period. The 
191 analytical region into small subregions. The stress tensor inversion has four unknown parameters: the three principal stress axes, $\sigma_{1}, \sigma_{2}, \sigma_{3}$, and the stress ratio:

$$
R=\left(\sigma_{1}-\sigma_{2}\right) /\left(\sigma_{1}-\sigma_{3}\right),
$$

194 which represents the relative stress magnitude. The uncertainties in the results were evaluated via 500 bootstrap resamplings (Michael 1987). The number of events used to estimate the uncertainty in each stress parameter was $\geq 20$ in each trial. As mentioned in Section 2.2, stress tensor inversions were not performed for each of the three temporal subwindows because there were too few available focal mechanisms.

\section{Results} The hypocenter distribution consists of a roughly NW-SE-oriented linear feature (Fig. 1).

202 There is no clear migration of events between periods 1 and 2 . The $b$-value cross-sections are first calculated for the events within $5.0 \mathrm{~km}$ of transect A-B in Fig. 1 during both analysis periods (Fig. 3)

204 based on the NW-SE alignment of the seismicity; this resolves depth-dependent characteristics with a transition at the mainshock depth $(9.5 \mathrm{~km})$. The shallower region has relatively high $b$-values $(b=0.7-$ 1.4) during both periods, whereas the $b$-values $(b=0.5-1.0)$ are lower in the deeper region (Fig. 3$)$. The

207 reduction in $b$-value $(b=0.5-0.7)$ is especially significant in the northwestern and southeastern parts of the deep region. Conversely, the characteristics of the $b$-values near the mainshock hypocenter differ slightly from the overall feature. The $b$-values $(b \sim 1.0)$ at $12.0-16.0 \mathrm{~km}$ depth (e.g., regions 1 and 5 in 
211 both periods; the $b$-values $(b \sim 0.7)$ are relatively low at $6.0-10.0 \mathrm{~km}$ depth and near the mainshock

212 hypocenter (region 3$)$ during period 1 compared to those $(b=1.0-1.4)$ in the surrounding shallow areas

213 (e.g., region 4); and the $b$-values increase $(b \sim 1.0)$ in the areas near the mainshock (e.g., regions 5 and 7 )

214 during period 2 (Fig. 3). Namely, low $b$-value areas at shallow depths near the mainshock are present

215 during period 1 but disappear during period 2. The observed spatial $b$-value heterogeneities for each

216 period are statistically significant at the $99 \%$ confidence level based on $p$-value tests (Utsu 1992), as

217 shown in Fig. 4.

Plan-view maps of the depth-dependent $b$-value characteristics are shown in Fig. 5 for the

219 shallow (0.0-9.5 km depth) and deep $(9.5-20.0 \mathrm{~km})$ regions during both periods, with the mainshock

220 depth serving as the transition between these two regions. The basic features are the same as those in the

221 cross-sections: the shallow region possesses relatively high $b$-values (Fig. 5a, c), whereas the $b$-values in

222 the deep region are low (Fig. 5b, d). This depth dependence is especially noticeable during period 2 . The

$223 b$-values in the northwestern and southeastern parts of the aftershock region in the deep region are lower

224 than those near the mainshock (Fig. 5b, d). The $b$-values in the shallow region near the mainshock are

225 lower than those in the surrounding shallow area during period 1 (Fig. 5a). Noticeable temporal increases

226 in the $b$-values are also observed in the shallow region (Fig. 5a, c), whereas significant temporal

227 variations are not found at greater depths (Fig. 5b, d).

230 the temporal changes in $b$-values; the corresponding $p$-values indicate that these changes are statistically

231 significant. The $b$-values also exhibit statistically significant temporal increases $(p \leq 0.0498)$ in many

232 parts of the shallow region, including the area near the mainshock (Fig. 6b). Areas with significant 
temporal $b$-value changes are not widely distributed at greater depths (Fig. 6d).

(Fig. S1). The general patterns in spatial and temporal distributions of $b$-values are the same as when the analysis window is divided into two periods (Figs. S2-S4). However, using three subwindows captures analysis (Figs. 3, 5, S2, and S3); the $b$-value distribution for period a2 appears to show a transition between periods 1 and 2. Most of the low $b$-values in the shallow region near the mainshock disappear

241 during period a2 (Figs. S2b and S3c). The observed low $b$-value anomaly may be characteristic of an early stage during period 1 . In addition, significant temporal increases in $b$-values between periods a1 and

243 a2 were found in many parts of the shallow region (Fig. S4a, b). $b$-values remained low at greater depths

244 during all three periods; areas with significant temporal $b$-value changes were not widely distributed (Fig. 245 S4c, d, g, h). The relationship between the $b$-values and focal mechanisms was then investigated (Figs. 5 and S3). The focal mechanisms for the $M \geq 3.5$ events, which are relatively large earthquakes for the

248 analyzed region, were located in the low $b$-value $(b=0.5-0.7)$ area of the deep region; this finding is

249 consistent with the definition of the $b$-value that moderate to large earthquakes are likely to occur in 250 regions with low $b$-value. A stress tensor inversion was performed for each period using these focal 251 mechanisms. The stress state obtained for period 1 was dominated by strike-slip fault type (Fig. 7), with $252 R=0.51$ and a $\mathrm{E}-\mathrm{W}$-oriented maximum principal stress. A counterclockwise rotation of the maximum 253 principal stress and changes in the stress ratio were determined for period 2, with a decrease in the stress ratio to $R=0.29$ and a ENE-WSW-oriented maximum principal stress. The rotation of the maximum 
principal stress was statistically significant at the $95 \%$ confidence level. This relatively low stress ratio

256 represents a stress state that is indicative of strike-slip/normal faulting (Fig. 7). This observation implies

257 that the stress state changed at greater depths, even though there were no significant temporal changes in $258 b$-values.

\section{Discussion} the 2005 West Off Fukuoka Prefecture Earthquake, with the stress-tensor inversion results indicating that the stress state below $9.5 \mathrm{~km}$ depth changed from a strike-slip-dominated to strike-slip/normal faulting regime. These results imply that the stress state is heterogeneous across the study area. Possible causes of the observed stress heterogeneity in the analyzed region are discussed in this section by comparing the results obtained in this study with those from previous studies. The areas with a high likelihood of nucleating large earthquakes are also evaluated. the $b$-value distributions. The shallow region possesses relatively high $b$-values, whereas the $b$-values in the deep region are low (Figs. 3 and 5). Uehira et al. (2006) reported that the aftershock distribution in the

271 central part of the study area was aligned on different fault planes that split at the mainshock depth, with a 272 difference of $\sim 10^{\circ}$ between their respective strikes and dips. Furthermore, they noticed that the mainshock 273 focal mechanism estimated from $P$-wave first-motion polarities was consistent with the deeper fault 274 plane, whereas the moment tensor solution estimated from broadband seismic waveform data

275 (Matsumoto, T. et al. 2006) was consistent with the shallower fault plane. The large coseismic slip of the 
mainshock was mainly observed in the southeastern part of the aftershock region, near the mainshock, at

277 shallower depths (e.g., Asano and Iwata 2006; Horikawa 2006). Uehira et al. (2006) suggested that the

278 mainshock rupture initiated at the hypocenter and propagated downward, then ruptured the lower plane

279 and propagated upward, with this last rupture segment releasing most of the associated seismic moment.

280 These findings suggest that more accumulated stress was released at shallower depths. The high $b$-values

281 in the shallow region can therefore be interpreted as a low-stress state associated with significant stress

282 release due to large coseismic slip. Nakao et al. (2006) found notable postseismic deformation on the

283 coseismic fault at $<3.0 \mathrm{~km}$ depth, with the postseismic slip on the fault accounting for up to $\sim 13 \%$ of the

284 coseismic slip. The $b$-values in the shallow region are especially high in the uppermost layers of Fig. 3.

285 These findings are all consistent with a low-stress state in the shallow region.

287 Kumamoto Earthquake is useful for understanding the potential causes of the $b$-value heterogeneities found in this study. The 16 April 2016 M 7.3 Kumamoto Earthquake occurred in the Futagawa-Hinagu fault zone, Kumamoto Prefecture, central Kyusyu, Japan. Nanjo et al. (2019) analyzed the $b$-value distribution after the mainshock in the focal region, and found a highly stressed area with low $b$-values at

291 the southern end of the causative faults. Their interpretation was that the heterogeneous $b$-values in the focal region were due to postseismic deformation. The focal region was located at the boundary between

293 an afterslip-dominated region and viscoelastic deformation-dominated region (Nanjo et al. 2019). They

294 suggested that there was a local increase in the stresses at the boundary between regimes dominated by different postseismic deformation processes based on the aftershock decay law of Utsu (1961) and a seismicity rate model inferred from the stressing history (Dieterich 1994). Compared with the Kumamoto earthquake, the postseismic deformation associated with the Fukuoka earthquake was restricted to very 
shallow depths in the focal region (e.g., Nakao et al. 2006). The significant temporal changes in $b$-values

299 in the present study are mainly found in the shallow region, where afterslip occurred. Nakao et al. (2006) detected postseismic deformation using GPS time-series data from 21 March to 27 June 2005. Significant postseismic deformation was clearly seen around the aftershock area during the analysis period of the present study (after 2005-04-20). In addition, the Geospatial Information Authority of Japan (GSI) (2006) reported that postseismic deformation ended in November 2005. These observations imply that significant postseismic deformation occurred during the early stage of period 1, which approximately corresponds to period a1 (2005-04-20-2005-08-31) in the three-subwindow analysis of the present study.

306 Evidently, significant temporal increases in $b$-values between periods a1 and a2 were observable in many 307 parts of the shallow region (Fig. S4a, b). Therefore, the postseismic deformation following a mainshock may play an important role in the temporal evolution of the $b$-values. Furthermore, the increase in $b$ -

309 values near the mainshock in the shallow region, which approximately corresponds to regions 3 and 7 in

310 Fig. 3, may also be ascribed to a decrease in the effective normal stress due to increased pore fluid

311 pressure, which will be discussed below. These findings indicate that it is unlikely that the shallow region 312 is the potential location of another large earthquake in the near future since a significant amount of stress 313 was released by coseismic and postseismic slip.

315 southeastern extension of the aftershock region appears to correspond to the northwestern edge of Kego

316 Fault, which extends beneath the Fukuoka metropolitan area (e.g., Okamura et al. 2009; Uehira et al.

317 2006). An evaluation of the stress state in the deeper region is therefore considered crucial for the 318 assessment of possible large earthquakes in the future. Matsumoto, S. et al. (2009) investigated the seismic-wave attenuation $\left(Q^{-1}\right)$ structure in and around the aftershock region of the 2005 mainshock, and 
discovered a highly heterogeneous $Q^{-1}$ structure in the focal region. Areas with large slip and high

321 aftershock activity were located in low $Q^{-1}$ regions, whereas high a $Q^{-1}$ region was found along the

322 southeastern edge of the aftershock region, near the largest aftershock. Matsumoto, S. et al. (2009)

323 suggested that the low and high $Q^{-1}$ regions corresponded to relatively high and low fault strengths,

324 respectively. The largest aftershock has the same strike angle as Kego Fault (Uehira et al. 2006).

325 Matsumoto, S. et al. (2009) posited a segment boundary between the mainshock fault and Kego Fault,

326 where the fault strength is weak, based on the difference between the strike angles of the mainshock and

327 largest aftershock. Iio et al. (2006) investigated the spatial distribution of the static stress drops of the

328 Fukuoka earthquake aftershocks from 23 March to 31 May 2005, and suggested the possibility of more

329 stress being concentrated along the southeastern edge of the aftershock region. The $b$-values along the

330 southeastern edge of the deeper region are consistent with the results of lio et al. (2006), and were low

331 throughout the entire analysis period (Figs. 3 and 5). These findings suggest that the southeastern extent

332 of the aftershock region, including the largest aftershock, comprises a highly stressed area with a

333 relatively low fault strength. This area may therefore have a high probability of experiencing a large

334 earthquake in the future compared to northwestern part of the aftershock region, even though both

335 subregions have low $b$-values. The potential causes of the relatively high $b$-values below the mainshock

336 are considered based on the findings of other geophysical studies. Wang and Zhao (2006) investigated the

337 3-D seismic velocity and Poisson's ratio structures in the epicentral area of the 2005 mainshock and

338 found that the mainshock was located at the boundary between high- and low-velocity regions in the

339 upper crust, with the lower crust side corresponding to a low-velocity, high Poisson's ratio region. They

340 interpreted the low-velocity region beneath the mainshock to possess fluids associated with mantle

341 upwelling due to the opening of Okinawa Trough. This finding suggests that fluids in and around a 
mainshock source area may play an important role in earthquake generation (Wang and Zhao 2006). The

343 relatively high $b$-values in the region beneath the mainshock are therefore considered to be generated by a

344 reduction in the effective normal stress due to abundant fluids in the focal region. The geophysical

345 interpretation of Wang and Zhao (2006) is helpful for inferring the cause of the temporal increase in $b$ -

346 values in the shallow region near the mainshock (regions 3 and 7 in Fig. 3). Fluid injection from the

347 deeper region may continue if this increase in $b$-values occurs due to an increase in pore pressure related

348 to the fluids beneath the focal region. northwestern and southeastern parts of the aftershock region, which possess low $b$-value areas in the

351 deeper region (Fig. 5). Unfortunately, the data are too sparse to invert for a stress tensor at each edge since only 13 and 10 events were available for periods 1 and 2, respectively. It should therefore be noted that the results of the stress tensor inversion show average stress states in both the deep northwestern and southeastern subregions during each period; despite this limitation, the inversion results revealed a change in the stress field that was characterized by counterclockwise rotation of the maximum principal stress axis and a change in $R$ from strike-slip to strike-slip/normal faulting. This change in $R$ is useful to infer

357 the differential stress near both edges of the aftershock region. The Coulomb failure criterion states that normal faulting events sustain the lowest differential stresses, strike-slip events are intermediate, and reverse faulting events have the highest stresses, assuming that the vertical stress is equal to the overburden pressure (e.g., Jaeger and Cook 1979). The observed change in $R$ implies that the average differential stress decreased slightly in these subregions during the study period. Areas with the low $b$ values appeared to decrease further during period 2 based on the $b$-value cross-sections and plan-view maps (Figs. 3b and 6c, respectively), although the decreases in the low $b$-value areas were not necessarily 
statistically significant at many nodes (Fig. 6d). The angle between the strike of the fault plane and maximum principal stress axis direction is used to infer the shear strength in the focal region (e.g.,

366 Hardebeck and Hauksson 2001). The maximum principal stress axis direction should be aligned $\sim 30^{\circ}$

367 relative to the fault plane for a strong fault, which is controlled by the frictional force (Byerlee 1978). On

368 the other hand, if the fault is weak, then the direction is predicted to be at a higher angle. The hypocenter

369 distribution consists of a roughly NW-SE-oriented linear feature (Fig. 1). Therefore, the angle of $\sigma_{1}$

370 relative to the mainshock fault strike was rotated, and increased, from period 1 to period 2 (Figs. $7 \mathrm{a}, \mathrm{c}$ ).

371 This finding also supports the observation of a slight decrease in average differential stress.

373 values is unknown because no significant postseismic deformation was observed in the deeper region

374 (Nakao et al. 2006). However, a region with significant low $b$-values does not necessarily lead to a future

375 large earthquake. For example, Tormann et al. (2015) analyzed the $b$-values along the subducting Pacific

376 Plate off Japan over a period that included the $2003 \mathrm{M}_{\mathrm{w}} 8.3$ Tokachi-oki and $2011 \mathrm{M}_{\mathrm{w}} 9.0$ Tohoku-oki

377 earthquakes, and found that the former occurred within an area of persistent low $b$-values off Hokkaido,

378 but not in a region of significant low $b$-values. On the other hand, the latter occurred within a subregion

379 of distinct low $b$-values in the subsequent high-slip area of the mainshock (Tormann et al. 2015). The

380 causes of these $b$-value differences remain unknown. Whether a significant decrease in $b$-value prior to a

381 major earthquake is an ubiquitous phenomenon is a question that should be approached with caution, as

382 some previous studies of major earthquakes found precursory increases in $b$-values (e.g., Smith 1981).

383 This point will be addressed in future research, where it can be considered in the context of other

384 geophysical studies. It is noteworthy, however, that El-Isa and Eaton (2014) reviewed previous research on spatial and temporal variations in $b$-values and found that the vast majority of previous papers support 
a decrease in $b$-value before a major earthquake. A significant and/or moderate decrease in $b$-value is

387 therefore useful information when drawing inferences about stress accumulation. Here the deeper region

388 along the southeastern edge of the aftershock region is considered to have a high likelihood of triggering

389 future large earthquakes due to the low $b$-values; however, there is a possibility that the differential stress

390 decreased slightly in the focal region. Temporal changes in the $b$-values that were related to the presence

391 of fluids were also found near the mainshock hypocenter. An increase in $b$-values related to a reduction in

392 effective stress, which is due to the presence of abundant fluids, may also be an important precursor to the

393 next large earthquake. Wiemer et al. (1998) reported that increased pore pressure lowered effective stress

394 and increased $b$-value, a phenomenon associated with the onset of an earthquake swarm at Long Valley

395 Caldera, California. The possibility that seismic activity increases due to abundant fluids in the focal

396 region cannot be ruled out.

\section{Conclusions}

This study examined the spatiotemporal $b$-value distributions in the aftershock region of the

2005 West Off Fukuoka Prefecture Earthquake. The $b$-value distributions possess distinct depth-

dependent characteristics, with the mainshock depth forming the transition zone. Relatively high $b$-values $(b=0.7-1.4)$ are distributed throughout the shallow region, whereas the $b$-values $(b=0.5-1.0)$ in the deep region are low. The high $b$-values in the shallow region are ascribed to significant stress release due

404 to large coseismic and postseismic slip. Although the $b$-values are generally low in the deep region, the 

parts of the aftershock region remained low throughout the analysis period, although a stress tensor inversion using focal mechanisms revealed a slight decrease in the average differential stress in these areas. It is possible that the southeastern part of the aftershock region possesses a high likelihood of hosting future large earthquakes.

\section{Acknowledgments}

414 The author used data from the Japan Meteorological Agency (JMA) unified earthquake catalog (h ttps://www.data.jma.go.jp/svd/eqev/data/bulletin/index.html). The ZMAP MATLAB software package (Wiemer 2001) (http://www.seismo.ethz.ch/static/stat_2010_website/stat-website-pre2010/www.earthq uake.ethz.ch/software/zmap.html) was used for the $b$-value analysis. The figures were prepared using the Generic Mapping Tools software package (Wessel et al. 2013). This study was partially funded by Tokio Marine Kagami Memorial Foundation, Japan (EAKF320500). The author thanks the editor Carla Braitenberg and two anonymous reviewers for helping to improve the manuscript.

\section{REFERENCES}

424 Aki, K. (1965). Maximum likelihood estimate of $\mathrm{b}$ in the formula $\log N=a-b M$ and its confidence limits. Bulletin of Earthquake Research Institute of the University of Tokyo, 43, 237-239. 
Bott, M. H. P. (1959). The mechanics of oblique slip faulting. Geological. Magazine, 96, 109-117.

429 Byerlee, J. (1978). Friction of rock. Pure and Applied Geophysics, 116, 615-4626.

430 Chiba, K. (2019). Spatial and temporal distributions of b-values related to long-term slow-slip and low-

431 frequency earthquakes in the Bungo Channel and Hyuga-nada regions, Japan. Tectonphysics, 757, 1-

432 9. https://doi.org/.10.1016/j.tecto.2019.02.021.

433 Chiba, K. (2020). Stress state along the western Nankai Trough subduction zone inferred from $b$-values,

434 long-term slow slip events, and low frequency earthquakes. Earth, Planets and Space, 72(3). https://doi.org/10.1186/s40623-020-1130-7.

Dieterich, J. (1994). A constitutive law for rate of earthquake production and its application to earthquake clustering. Journal of Geophysical Research, 99(B2), 2601-2618. https://doi.org/10.1029/93JB02581.

El-Isa, Z.H. \& Eaton, D.W. (2014). Spatiotemporal variations in the $b$-value of earthquake magnitudehttps://doi.org/.10.1016/j.tecto.2013.12.001.

Frohlich, C., \& Davis, S. (1993). Teleseismic b values; or, much ado about 1.0. Journal of Geophysical Research, 98(B1), 631-644.

443 Geospatial Information Authority of Japan. (2006). Crustal deformation and a fault mode of the West 444 off Fukuoka Prefecture Earthquake in 2005. https://www.gsi.go.jp/common/000025591.pdf (in 445 Japanese).

446 Gephart, J. W., \& Forsyth, D. W. (1984). An improved method for determining the regional stress tensor 447 using earthquake focal mechanism data: Application to the San Fernando earthquake sequence. $448 \quad$ Journal of Geophysical Research, 89, 9,305-9,320.

449 Ghosh, A., Newman, A.V., Thomas, A.M., \& Farmer, G.T. (2008). Interface locking along the 
452 Gulia, L., \& Wiemer, S. (2019). Real-time discrimination of earthquake foreshocks and aftershocks.

$453 \quad$ Nature, 574, 193-199. https://doi.org/10.1038/s41586-019-1606-4.

454 Gutenberg, B., \& Richter, C. F. (1944). Frequency of earthquakes in California. Bulletin of the 455 Seismological Society of America, 34, 185-188.

456 Hardebeck, J.L., \& Hauksson, E. (2001). Crustal stress field in southern California and its implications 457 for fault mechanics. Journal of Geophysical Research, 106(B10), 21,859-21.882.

458 Hardebeck, J. L., \& Michael, A. J. (2006). Damped regional-scale stress inversions: Methodology and 459 examples for southern California and the Coalinga aftershock sequence. Journal of Geophysical $460 \quad$ Research, 111, B11310. https://doi.org/10.1029/2005JB004144.

Horikawa, H. (2006). Rupture process of the 2005 West Off Fukuoka Prefecture, Japan, earthquake. Earth, Planets and Space, 58, 87-92.

Iio, Y., Katao, H., Ueno, T., Enescu, B., Hirano, N., Okada, T., Uchida, N., Matsumoto, S., Matsuhima, T., Uehira, K., \& Shimizu, H. (2006). Spatial distribution of seismic stress drops for aftershocks of the 2005 West Off Fukuoka Prefecture Earthquake. Earth, Planets and Space, 58, 1611-1615. demiement. Bulletin of the Earthquake Research Institute, Tokyo Imperial University, 17, 443-478. London. for stress inversion combining solid classic methodology, a new simplified user-handling and a 
473 Matsumoto, S., Uehira, K., Watanabe, A., Goto, K., Iio, Y., Hirata, N., Okada, T., Takahashi, H.,

474 Shimizu, H., Shinohara, M., \& Kanazawa, T. (2009). High resolution $Q^{-1}$ estimation based on

475 extension of coda normalization method and its application to $P$-wave attenuation structure in the

476 aftershock area of the 2005 West Off Fukuoka Prefecture Earthquake (M 7.0). Geophysical Journal

477 International, 179, 1039-1054. https://doi.org/10.1111/j.1365-246X.2009.04313.x.

478 Matsumoto, T., Ito, Y., Matsubayashi, H., \& Sekiguchi, S. (2006). Spatial distribution of F-net moment

479 tensors of the 2005 West Off Fukuoka Prefecture Earthquake determined by the extended method of 480 the NIED F-Net routine. Earth Planets Space, 58, 63-67.

481 Michael, A. J. (1984). Determination of stress from slip data: Faults and folds. Journal of Geophysical $482 \quad$ Research, 89, 11,517-11,526.

483 Michael, A.J. (1987). Stress rotation during the Coalinga aftershock sequence. Journal of Geophysical $484 \quad$ Research, 92, 7,963-7,979.

Mogi, K. (1962). Magnitude-Frequency relation for elastic shocks accompanying fractures of various materials and some related problems in earthquakes. Bulletin of the Earthquake Research Institute, University of Tokyo, 40, 831-853.

Nakao, S., Takahashi, H., Matsushima, T., Kohno, Y., \& Ichiyanagi, M. (2006). Postseismic deformation following the 2005 West Off Fukuoka Prefecture Earthquake (M7.0) derived by GPS observation.

491 Nanjo, K. Z., Ishibe, T., Tsuruoka, D., Schorlemmer, D., Ishigaki, Y., \& Hirata, N. (2010). Analysis of 492 the Completeness Magnitude and Seismic Network Coverage of Japan. Bulletin of the Seismological Society of America, 100(6), 3261-3268. https://doi.org/10.1785/0120100077. 
494 Nanjo, K. Z., Izutsu, J., Orihara, Y., Furuse, N., Togo, S., Nitta, H., Okada, T., Tanaka, R., Kamogawa, 495 M., \& Nagao, T. (2016). Seismicity prior to the 2016 Kumamoto earthquakes. Earth, Planets and Space, 68, 187. https://doi.org/10.1186/s40623-016-0558-2.

497

Nanjo, K.Z., \& Yoshida, A. (2018). A b map implying the first eastern rupture of the Nankai Trough earthquakes. Nature Communications, 9, 1117. https://doi.org/10.1038/s41467-018-03514-3.

Nanjo, K.Z., Izutsu, J., Orihara, Y., Kamogawa, Y., \& Nagano, T. (2019). Changes in seismicity pattern due to the 2016 Kumamoto Earthquakes identify a highly stressed area on the Hinagu fault zone. Geophysical Research Letters, 46(16). https://doi.org/10.1029/2019GL083463. earthquake probability due to fault interaction. https://www.aist.go.jp/Portals/0/resource_images/ aist_j/aistinfo/aist_today/vol05_05/vol05_05_p14_15.pdf (in Japanese). 2005 Fukuoka-ken Seiho-oki earthquake estimated from coseismic deformation observed by GPS and InSAR. Earth, Planets and Space, 58, 51-56. 190. (in Japanese).

Scholz, C. H. (1968). The frequency-magnitude relation of microfracturing in rock and its relation to earthquakes. Bulletin of the Seismological Society of America, 58, 399-415.

513 Scholz, C. H. (2015). On the stress dependence of the earthquake b value. Geophysical Research Letters, 42, 1399-1402. https://doi.org/10.1002/2014GL062863. 
517 Schorlemmer, D., \& Wiemer, S. (2005). Microseismicity data forecast rupture area. Nature, 434, 1086. https://doi.org/10.1038/4341086a.

Shimizu, H., Takahashi, T., Okada, T., Kanazawa, T., Iio, Y., Miyamachi, H., Matsushima, T., Space, 58, 1599-1604.

Shimoyama. S., Iso, N., Matsuda, T., Ichihara, T., Chida, N., Okamura, M., Mogi, T., Suzuki, S., Ochiai, Research, 25, 117-128. https://doi.org/10.1038/289136a0. University of Tokyo Press, (in Japanese).

534 Tormann, T., Enescu, B., Woessener, J., \& Wiemer, S. (2015). Randomness of megathrust earthquakes 535 implied by rapid stress recovery after the Japan earthquake. Nature Geoscience, 8(2), 152-158. $536 \quad$ https://doi.org/10.1038/ngeo2343. 
$538(\mathrm{Mj}=7.0)$ by using a dense onshore and offshore seismic network. Earth, Planets and Space, 58,

$539 \quad 1605-1610$.

540 Urbancic, T.I., Trifu, C. I., Long, J. M., \& Young, R. P. (1992). Space-time correlations of b values with

$541 \quad$ stress release. Pure and Applied Geophysics, 139(3), 449-462.

542 Utsu, T. (1961). A statistical study on the occurrence of aftershocks. Geophysics, 30. 521-605.

543 Utsu, T. (1992). On seismicity, in: Report of Cooperative Research of the Institute of Statistical

$544 \quad$ Mathematics. The Institute of Statistical Mathematics Tokyo, 34, 139-157.

545 Utsu, T. (1999). Representation and analysis of the earthquake size distribution: A historical review and

$546 \quad$ some approaches. Pure and Applied Geophysics, 155, 509-535.

547 Wallace, R. E. (1951). Geometry of shearing stress and relationship to faulting. The Journal of Geology,

$548 \quad 59,111-130$.

549 Wang, Z., \& Zhao, D. (2006). Seismic evidence for the influence of fluids on the 2005 west off Fukuoka

550 prefecture earthquake in southwest Japan. Physics of the Earth and Planetary Interiors, 155, 313-324.

551 Warren, N. W., \& Latham, G. V. (1970). An experimental study of thermally induced microfracturing

552 and its relation to volcanic seismicity. Journal of Geophysical Research, 75, 4455-4464.

553 https://doi.org/10.1029/JB075i023p04455.

554 Wessel, P., Smith, W. H. F., Scharroo, R, R., Luis, J. F., \& Wobbe, F. (2013). Generic Mapping Tools:

555 improved version released. Eos, Transactions American Geophysical Union, 94, 409-410.

556 https://doi.org/10.1002/2013EO450001.

557 Wiemer, S. (2001). A software package to analyze seismicity: ZMAP. Seismological Research Letters, $558 \quad 72(3), 373-382$.

559 Wiemer, S., \& Wyss, M. (2000). Minimum magnitude of completeness in earthquake catalogs: examples 
560 from Alaska, the Western United States, and Japan. Bulletin of the Seismological Society of America,

$56190,859-869$.

562 Wiemer, S., McNutt, S.R., \& Wyss, M. (1998). Temporal and three-dimensional spatial analyses of the

563 frequency-magnitude distribution near Long Valley Caldera, California. Geophysical Journal

564 International, 134, 409-421. https://doi.org/10.1406/j.1365-246x.1998.00561.x.

565 Woessner, J., \& Wiemer, S. (2005). Assessing the quality of earthquake catalogues: estimating the

566 magnitude of completeness and its uncertainty. Bulletin of the Seismological Society of America,

567 95(2), 684-498. https://doi.org/10.1785/0120040007.

568 Wyss, M. (1973). Towards a physical understanding of the earthquake frequency distribution.

569 Geophysical Journal of the Royal Astronomical Society, 31, 341-359. htpps://doi.org/10.1111/j.1365-

570 246X.1973.tb06506.x.

571 
575 Left: Epicentral distribution of the $\mathrm{M} \geq 0.5$ earthquakes. The red and green circles represent the period 1 . 576 (12:20 JST on 20 April 2005 to 23:59 on 31 December 2005) and period 2 (00:00 JST on 1 January 2006 to 23:59 on 31 January 2020) events, respectively. The events are scaled by their magnitudes. The yellow and blue stars represent the hypocenters of the mainshock and largest aftershock $\left(\mathrm{M}_{\mathrm{J}} 5.8,06: 11 \mathrm{JST}\right.$ on 20 April 2005), respectively. The yellow and blue focal mechanisms are those for the mainshock and largest aftershock, respectively. The red lines indicate active faults (The Research Group for Active Faults of Japan 1991). Line A-B shows the location of the $b$-value cross-section in Fig. 3. The red rectangle represents the region used for $b$-value analysis in Figs. 5 and 6. The inset map shows the analyzed region with respect to western Japan. Right: Cross-section of the hypocenters within $5 \mathrm{~km}$ of A-B.

586 (a) $M_{c}$ as a function of time in the area bordered by the red rectangle in Fig. 1. The dashed gray lines 587 represent the standard deviation of the calculated $M_{c}$ values. The maximum curvature method (Wiemer and Wyss 2000) was employed to investigate the $M_{c}$ distribution in the study area using overlapping

589 500-event windows and a 20-event step. (b) Spatial distribution of $M_{c}$ estimated using the maximum 590 curvature method (Wiemer and Wyss 2000) with $0.5 \mathrm{~km}$ grid spacing and a constant sampling radius of $5912.5 \mathrm{~km}$. The yellow and blue stars represent the mainshock and the largest aftershock, respectively. 
594 Cross-sections of the $b$-values in (a) period 1 and (b) period 2. The yellow and blue stars represent the 595 mainshock and the largest aftershock, respectively. The black circles show the regions where the $p$-value 596 test was performed. The small black circles represent the events that occurred in each region. of events that occurred each region.

601

603 (a, b) Plan-view $b$-value maps of the shallow (0.0-9.5 km depth) and deep (9.5-20.0 km depth) regions

604 during period 1. (c, d) Plan-view $b$-value maps of the shallow and deep regions during period 2. The focal mechanisms from the F-net data are superimposed on the $b$-value maps for the appropriate depth range and time window. The sizes of the focal mechanisms are proportional to their moment magnitudes. The other symbols and meanings are the same as in Fig. 1.

608

610 (a) Difference in $b$-values between the first and second periods $\left(\Delta b=b_{\text {period } 2}-b_{\text {period } 1}\right)$ in the shallow

611 region. (b) $p$-values estimated from $\Delta b$ in (a). (c) Difference in $b$-values in the deep region. (d) $p$-values 612 estimated from $\Delta b$ in (c). The other symbols and meanings are the same as in Fig. 1. 
615 Stress tensor inversion results for (a) period 1 and (b) period 2. The large square, triangle, and circle

616 show the best orientations of the maximum, intermediate, and minimum principal stresses, respectively.

617 The small red, green, and blue circles represent the $95 \%$ confidence limits of the $\sigma_{1}, \sigma_{2}$, and $\sigma_{3}$ axis

618 orientations, respectively. The right figures show frequencies of the stress ratios $R$ within the $95 \%$

619 confidence limits. 


\section{Figures}

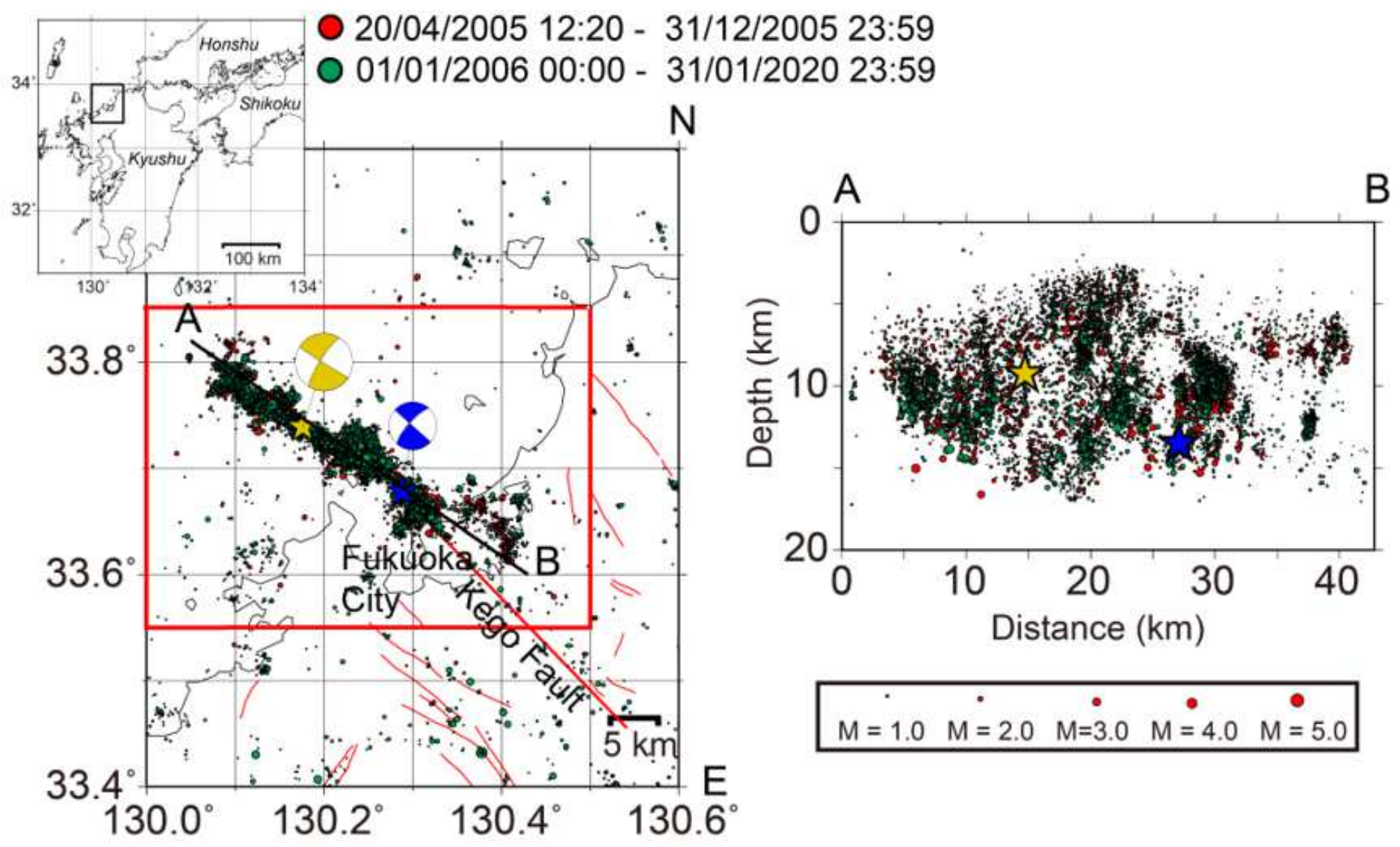

Figure 1

Left: Epicentral distribution of the $M \geq 0.5$ earthquakes. The red and green circles represent the period 1 (12:20 JST on 20 April 2005 to 23:59 on 31 December 2005) and period 2 (00:00 JST on 1 January 2006 to 23:59 on 31 January 2020) events, respectively. The events are scaled by their magnitudes. The yellow and blue stars represent the hypocenters of the mainshock and largest aftershock (MJ 5.8, 06:11 JST on 20 April 2005), respectively. The yellow and blue focal mechanisms are those for the mainshock and largest aftershock, respectively. The red lines indicate active faults (The Research Group for Active Faults of Japan 1991). Line A-B shows the location of the b-value cross-section in Fig. 3 . The red rectangle represents the region used for b-value analysis in Figs. 5 and 6 . The inset map shows the analyzed region with respect to western Japan. Right: Cross-section of the hypocenters within $5 \mathrm{~km}$ of A-B. 
(a)

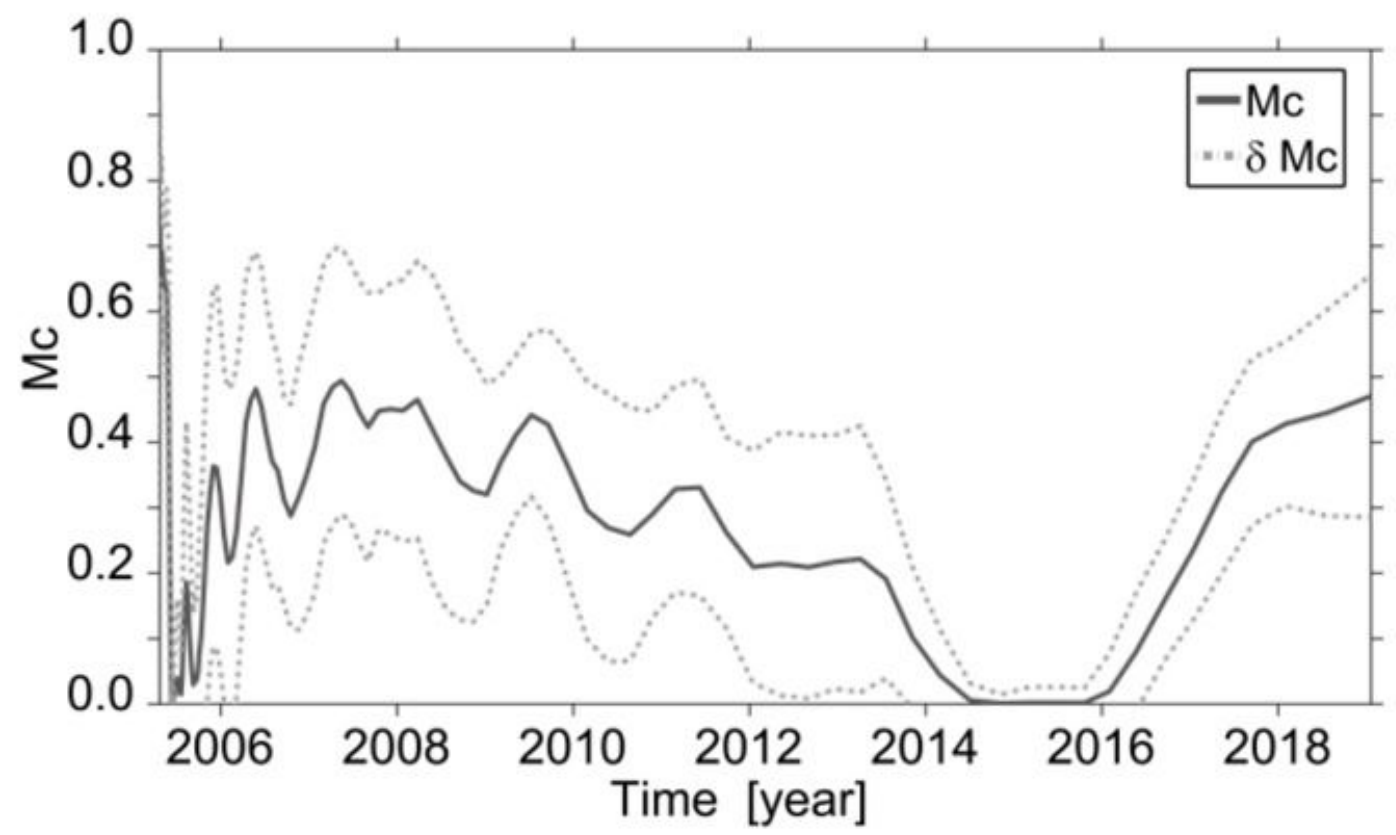

(b)

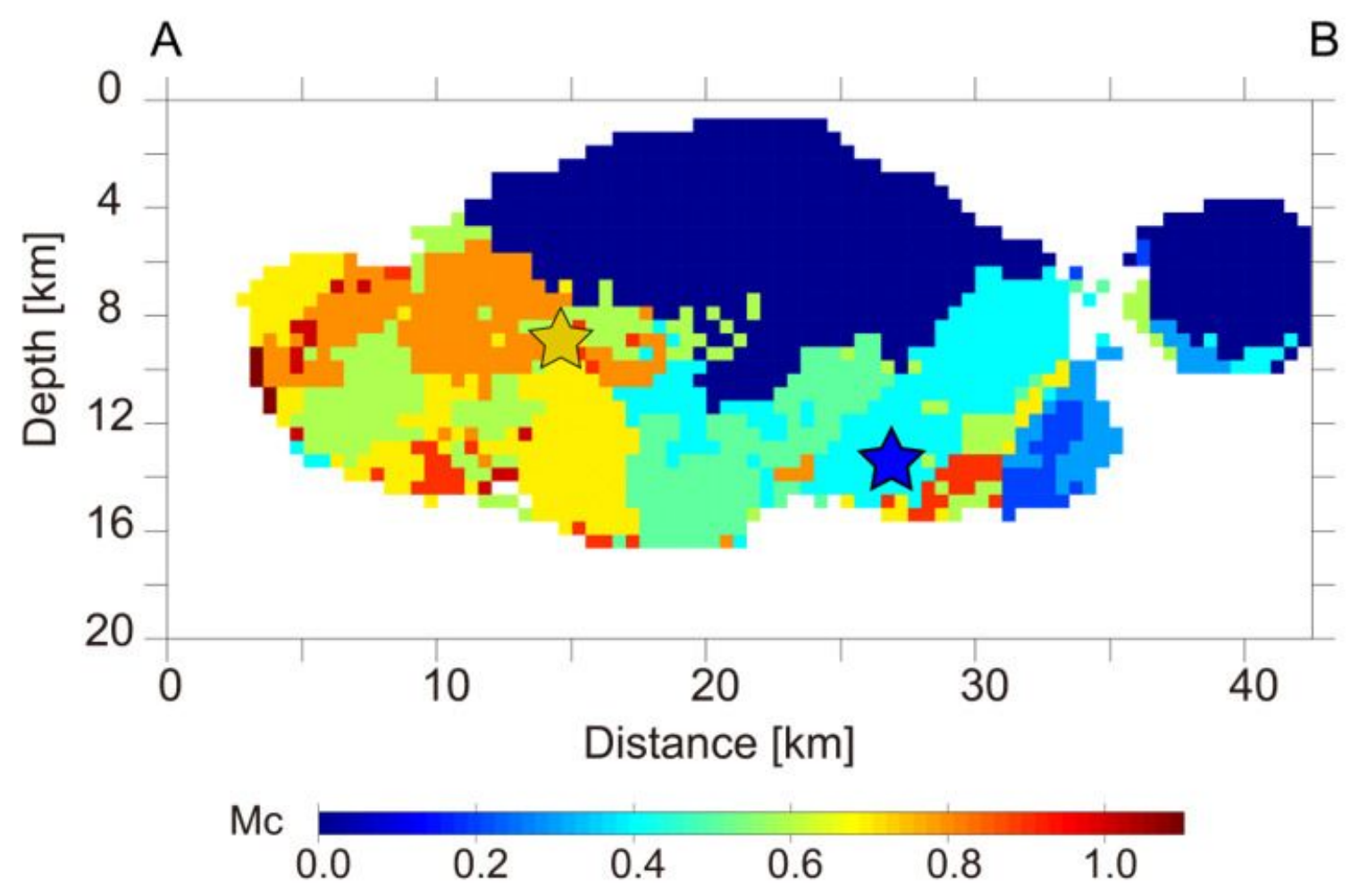

Figure 2

(a) Mc as a function of time in the area bordered by the red rectangle in Fig. 1. The dashed gray lines represent the standard deviation of the calculated Mc values. The maximum curvature method (Wiemer and Wyss 2000) was employed to investigate the Mc distribution in the study area using overlapping 500event windows and a 20-event step. (b) Spatial distribution of Mc estimated using the maximum 
curvature method (Wiemer and Wyss 2000) with $0.5 \mathrm{~km}$ grid spacing and a constant sampling radius of $2.5 \mathrm{~km}$. The yellow and blue stars represent the mainshock and the largest aftershock, respectively.
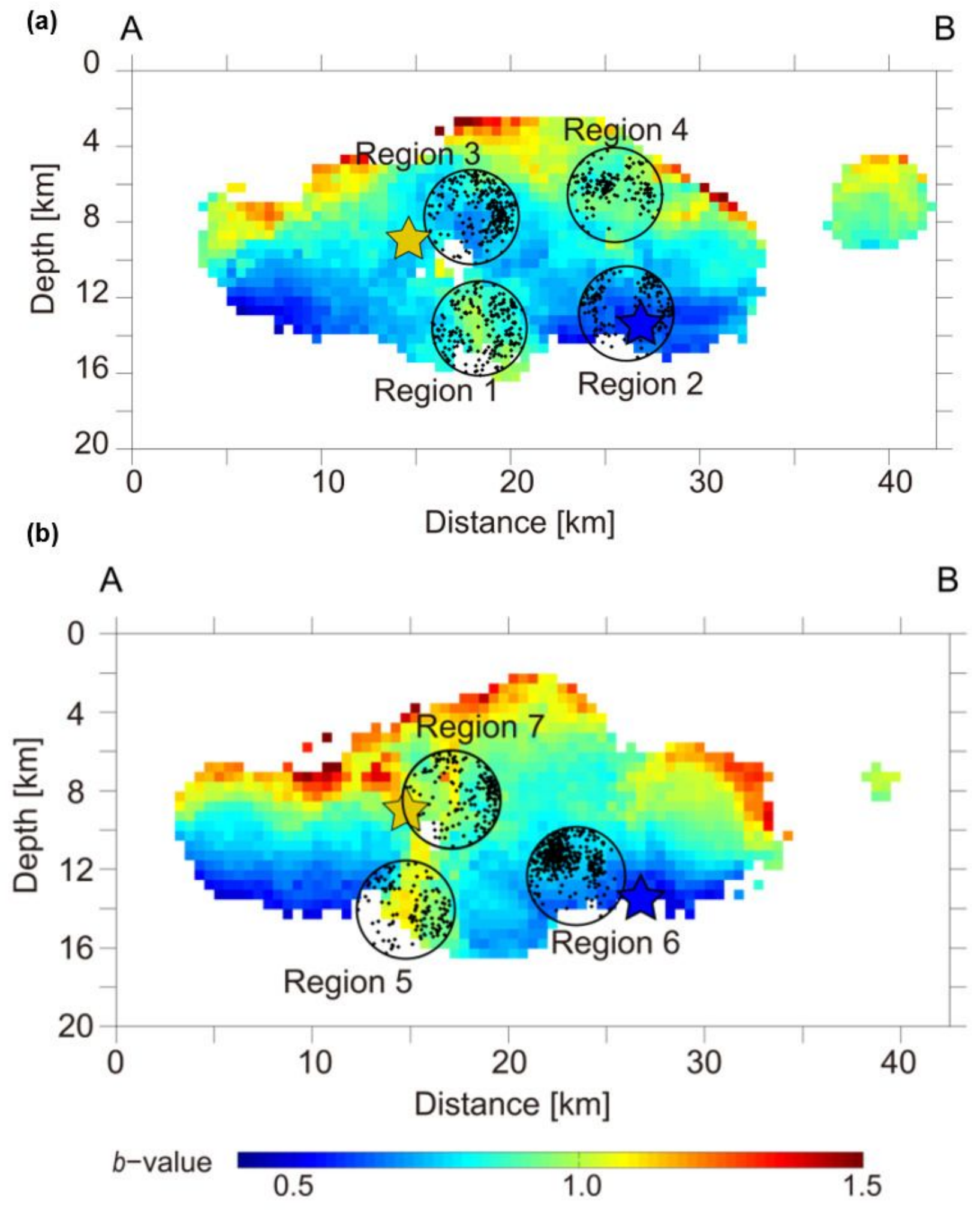

Figure 3

Cross-sections of the b-values in (a) period 1 and (b) period 2. The yellow and blue stars represent the mainshock and the largest aftershock, respectively. The black circles show the regions where the $p$-value test was performed. The small black circles represent the events that occurred in each region. 
(a)

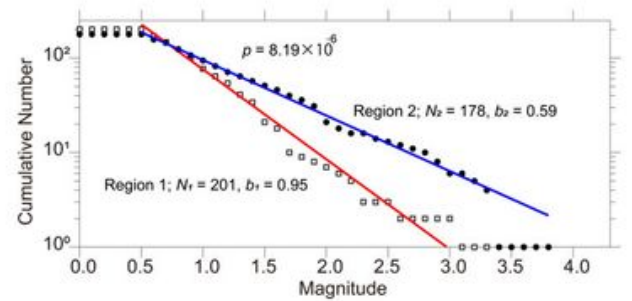

(b)

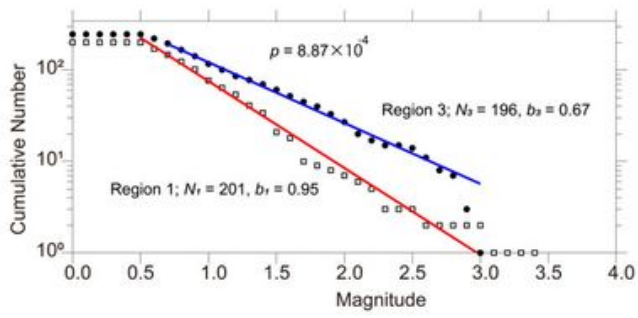

(c)

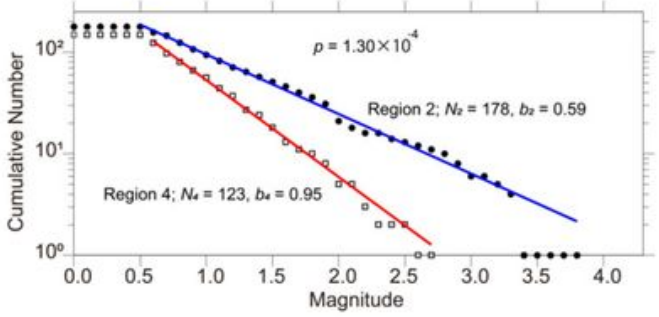

(d)

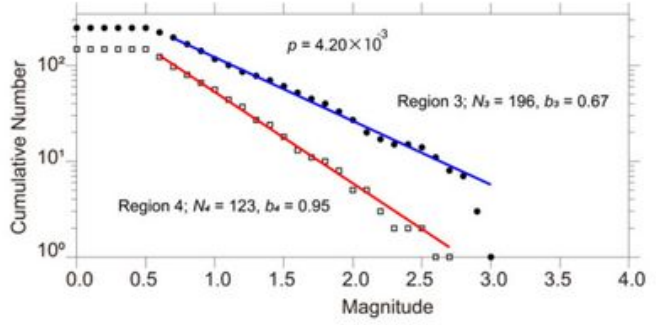

(e)

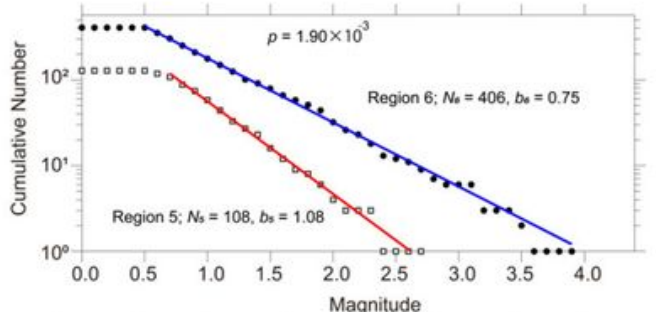

(f)

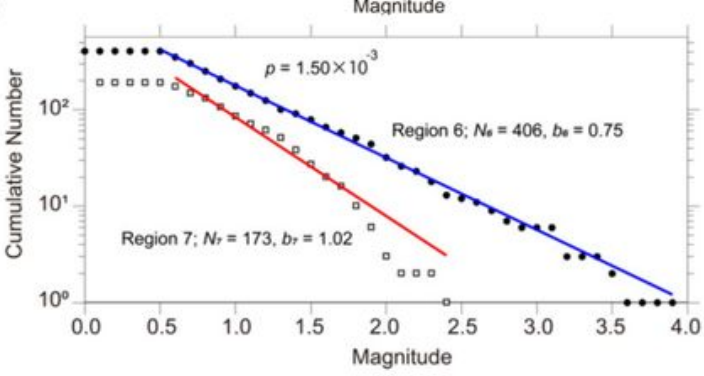

\section{Figure 4}

p-values for the regions with different b-values: $(a-d)$ period $1 ;(e, f)$ period $2 . \mathrm{N}$ represents the number of events that occurred each region. 
(a) 20/04/2005 12:20 - 31/12/2005 23:59

(b)
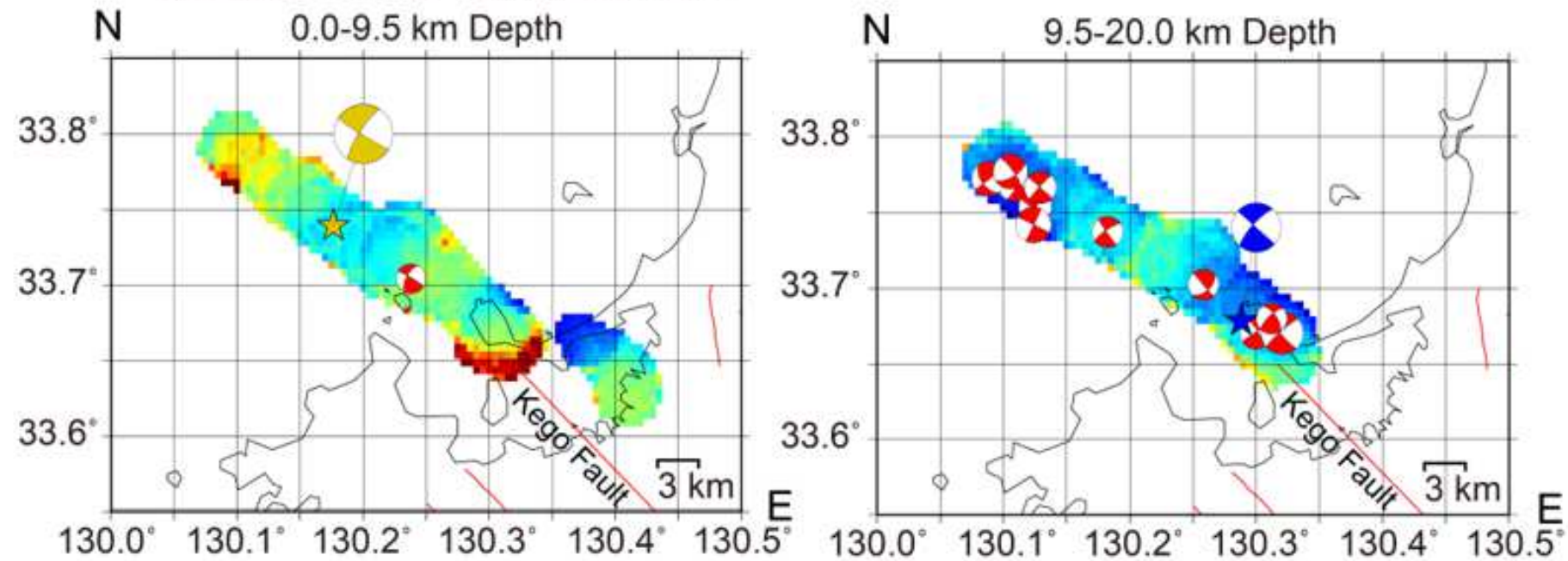

(c) $01 / 01 / 200600: 00-31 / 01 / 202023: 59$

(d)
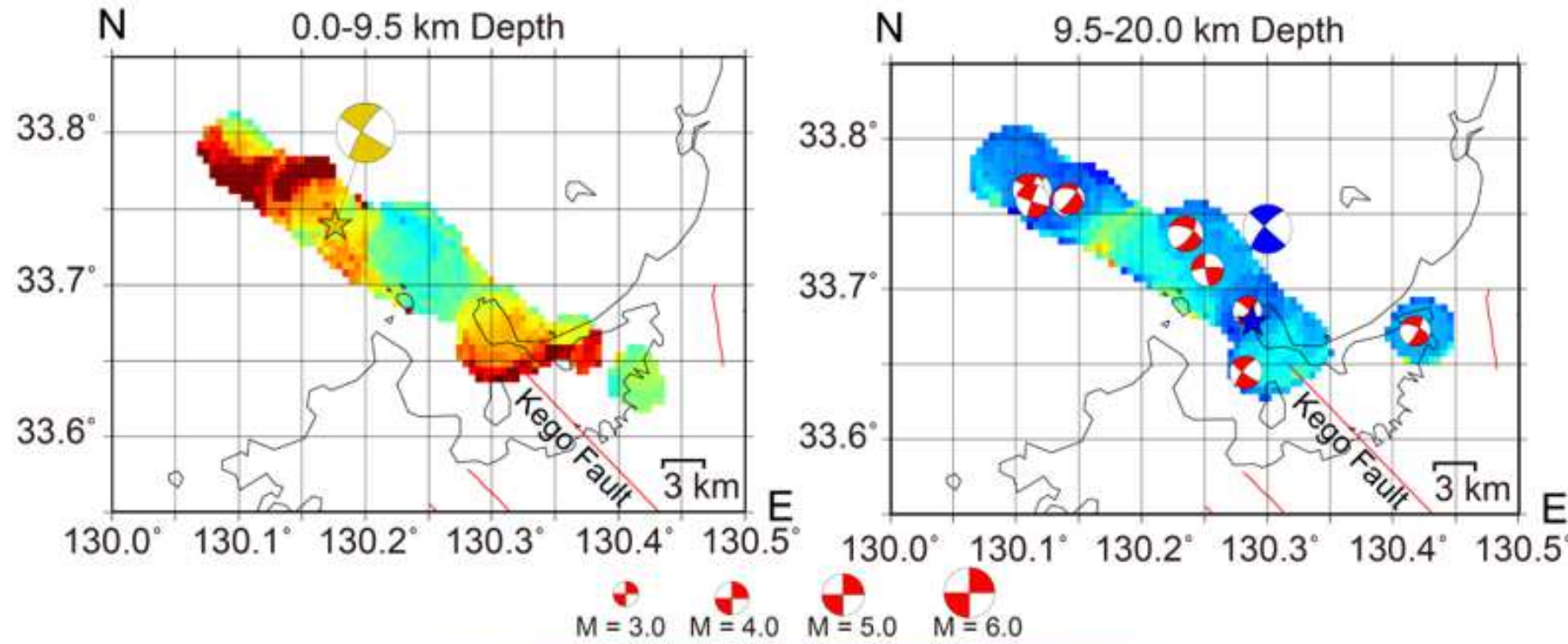

$b$-value

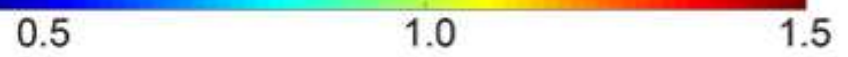

Figure 5

$(a, b)$ Plan-view b-value maps of the shallow (0.0-9.5 km depth) and deep (9.5-20.0 km depth) regions during period 1. (c, d) Plan-view b-value maps of the shallow and deep regions during period 2. The focal mechanisms from the F-net data are superimposed on the b-value maps for the appropriate depth range and time window. The sizes of the focal mechanisms are proportional to their moment magnitudes. The other symbols and meanings are the same as in Fig. 1. 
(a)

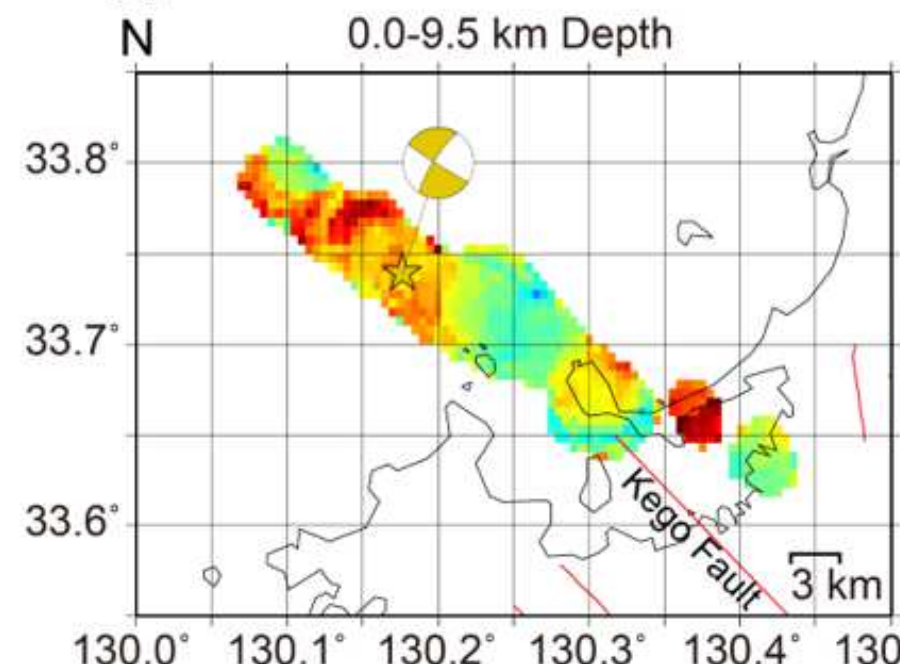

(c)

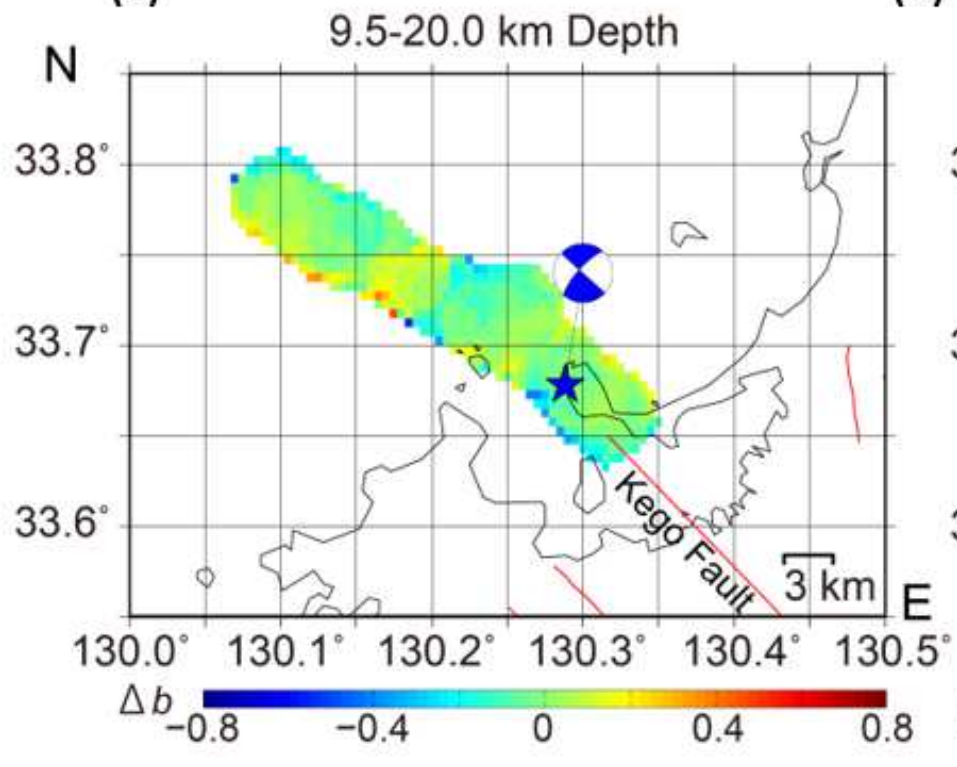

(d) (b)
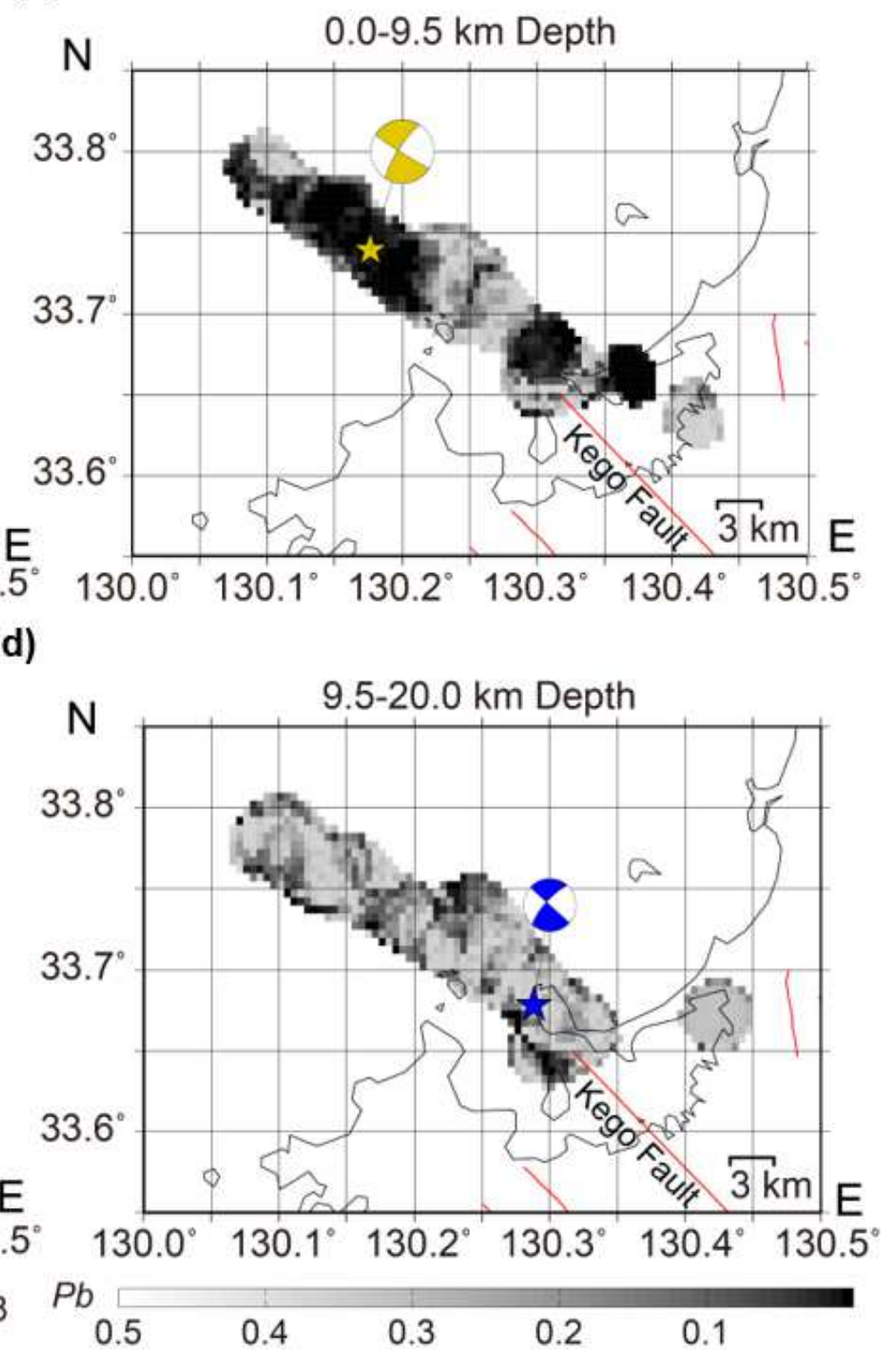

Figure 6

(a) Difference in $b$-values between the first and second periods ( $\Delta b=$ b_period2-b_period1) in the shallow region. (b) $p$-values estimated from $\Delta b$ in (a). (c) Difference in b-values in the deep region. (d) p-values estimated from $\Delta b$ in (c). The other symbols and meanings are the same as in Fig. 1. 
(a)
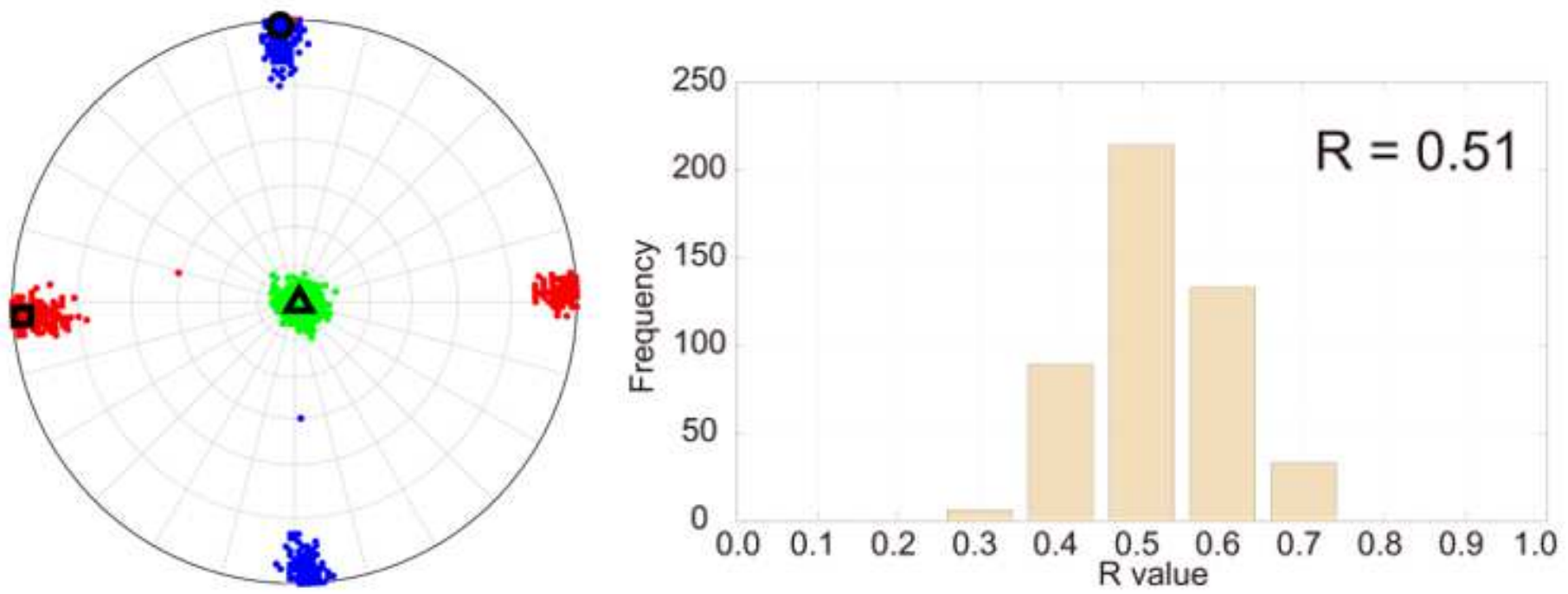

(b)
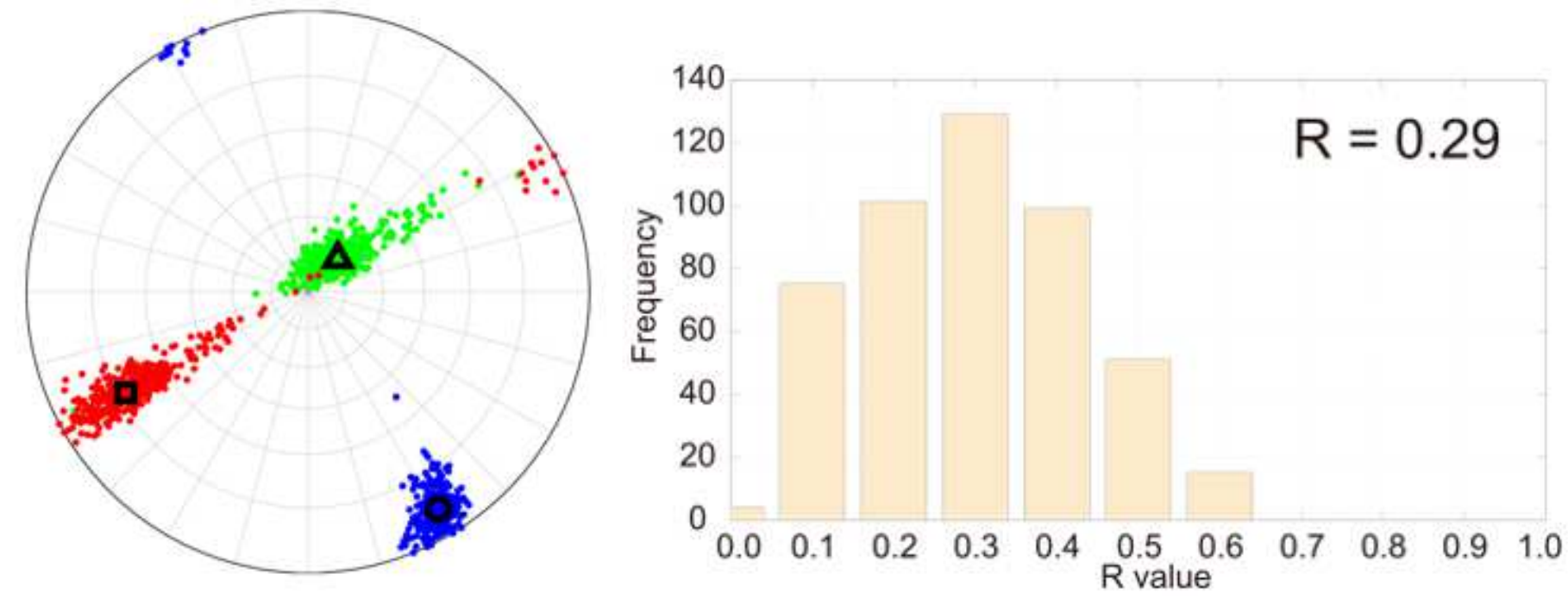

$\mathbf{\square} \sigma_{1}$ axis $\boldsymbol{\Delta} \sigma_{2}$ axis $\mathbf{O} \sigma_{3}$ axis

\section{Figure 7}

Stress tensor inversion results for (a) period 1 and (b) period 2. The large square, triangle, and circle show the best orientations of the maximum, intermediate, and minimum principal stresses, respectively. The small red, green, and blue circles represent the $95 \%$ confidence limits of the $\sigma_{-} 1, \sigma_{-} 2$, and $\sigma_{-} 3$ axis orientations, respectively. The right figures show frequencies of the stress ratios $\mathrm{R}$ within the $95 \%$ confidence limits.

\section{Supplementary Files}

This is a list of supplementary files associated with this preprint. Click to download. 
- PAAGD2000347appendixR1.docx 